\title{
LAS PRIMERAS FÁBRICAS DE HARINA, UN EJEMPLO DE ARQUEOLOGÍA AGROINDUSTRIAL
}

\author{
(OLD FLOUR FACTORIES, AN EXAMPLE OF AGRO-INDUSTRIAL ARCHAEOLOGY)
}

Francisco Ayuga Téllez y Ana Isabel García y García, Profs. Titulares de la ETS de Ingenieros Agrónomos de Madrid

Fecha de recepción: $27-$ VI-97

ESPAÑA

\section{RESTMIEN}

Las fábricas de harina de finales del siglo XLX y primer tercio del XX son edificios de gran belleza, enclavados en nucleos rurales muy diversos y que se encuentran en España en un número muy apreciable. Sufren olvido y abandono, pero en la mayoria de los casos su estado de conservación es bueno y sus posibilidades de reutilización muy amplias. En este articulo se repasa su motivación histórica y sus caracteristicas de diseño $v$ construcción, haciendo mención de su influencia en la construcción rural en el pasado y de sus posibilidades de futuro.

\section{SUMMARY}

Flour factories of the latest XLXth century and first third of XXth century are buildings of a great beauty. They are set in very different rural towns. In Spain there are a great number of them. They are mainly forgotten and abandoned, although their preservation is fair good and there are wide reuse possibilities.. In this paper its history reason and its design and construction characteristics are analysed. It is also mentioned its influence on rural construction in the past and its future possibilities.

\section{Antecedentes históricos}

Desde muy antiguo, en la alimentación de los pueblos mediterráneos el pan de trigo constituye el alimento básico y principal. Realmente en todos los pueblos algún cereal cumple esta misión, llámese arroz, mijo, maíz, etc. Las tierras europeas cultivadas estuvieron durante siglos mayoritariamente dedicadas a la producción triguera. En el proceso de transformación del trigo en pan, la primera tarea es la obtención de la harina y por esto su importancia es trascendental.

Las técnicas de molienda del trigo se remontan a la prehistoria. Todavía hoy en determinadas regiones del mundo se realiza esta molienda de forma manual, pero en el área mediterránea pronto se empezó a usar la tracción animal para tan ingrata tarea. La civilización de la Roma clásica diseñó (como en casi todos los aspectos tecnológicos) el sistema de molienda que, con levísimos cambios, se ha mantenido durante siglos. Son los malacates, que, en esencia, consisten en un eje vertical de madera con dos pivotes, uno en el suelo y otro en el techo, una vara horizontal con una horquilla, a la que se sujetaba el animal (o el esclavo, porque los romanos usaban indistintamente a ambos) y dos piedras o "muelas", una fija inferior o piedra de solera y otra móvil superior o piedra volandera. El trigo se introduce por el centro y se desplaza y muele hasta salir por los extremos. La harina resultante se criba, separándose el salvado, pudiendo volver a molerse para aumentar la finura final. Manteniendo el mismo esquema se produce una evolución en la forma de las piedras, desde los troncos de cono en los romanos a las formas cilindricas planas, más fáciles de labrar y que perdurarán hasta casi nuestro siglo. 
Con el progreso de las ideas cristianas y el decaimiento de la esclavitud se empieza a pensar en la sustitución de la tracción humana en la molienda del trigo. Pronto (quizá por la influencia de la cultura islámica) se introduce el uso del agua como elemento motor. Esto produce una especialización del trabajo de fabricación de harinas que pasa de ser una tarea de cada cultivador a convertirse en un oficio, el de molinero, que alquila su instalación o cobra por su trabajo del dueño del molino, que suele ser la Iglesia o los señores feudales. La razón principal es que la ubicación de los molinos queda predeterminada por las condiciones y situación de los cursos de agua. La molienda se realiza mediante muelas, igual que en los malacates, pero el accionamiento de las mismas se hace mediante ruedas de madera que reciben la energía de otra rueda de mayor diámetro, con paletas embreadas que, adecuadamente introducidas en una corriente de agua, la hacen girar. En muchas ocasiones no se puede disponer de las condiciones de corriente idóneas por lo que se precisa, además, la construcción de azudes o presas y canales de derivación. Así, no todo el mundo puede disponer de estas instalaciones y los que lo hacen, se convierten en molineros.

Se completan los edificios con la vivienda del molinero, mucho más sencilla que la de los agricultores y que puede estar en la planta baja o en el segundo piso.

La ventaja de los molinos de agua frente al tradicional malacate es evidente: se ahorra energía y se racionaliza el trabajo. Sin embargo,, no llegaron a desaparecer totalmente los sistemas de molienda en explotaciones particulares.

Estos molinos de agua han sido objeto de estudio en diversas ocasiones, por la peculiaridad de sus tipologías constructivas, su racionalidad tecnológica y también por la belleza de los parajes en los que se enclavan. Varias Comunidades Autónomas están interesadas en su recuperación y acondicionamiento pensando, fundamentalmente, en actividades recreativas o turísticas.

Más tardíamente aparece otra fuente de energía aplicada a la molienda de trigo. Se trata de la energía eólica, que se utiliza en los molinos de viento. Su origen es muy discutido, pero su expansión se produce en España durante el siglo XVI. En Europa se conocen desde el siglo XII.

Los molinos de viento tienen un gran interés, y no sólo por su transcendencia literaria y poética, sino también desde el punto de vista tecnológico. Ciertas ideas del diseño de estos molinos se trasladan a las fábricas de harinas del siglo XIX y XX. Concretamente sucede así con la disposición en distintas alturas de las fases de fabricación (molienda y cernido).

La mayoría de los molinos de viento españoles se construyeron y explotaron para la molienda del trigo en la zona manchega. Estos molinos son de planta circular, con gruesas paredes de mampostería, prolongadas como cimentación en el terreno, con alturas entre 6 y 8 metros. La cubierta es un cono giratorio que sirve para orientar las aspas según la dirección del viento. Para moverla se empuja desde el exterior un grueso y largo madero que se fija a unas piedras que rodean circularmente al molino. Para averiguar la dirección del viento se emplean ventanitas abiertas en las paredes, lo más elevadas posible y en número de cuatro, ocho o dieciséis. Se accede a ellas desde el piso superior, en el que también está la transmisión del movimiento a un eje vertical, a través de una rueda de madera. Las muelas y el sistema de aproximación entre ellas, así como el freno de las aspas, están en este nivel. En un piso más bajo se sitúan los cernedores del producto molido. Una escalera estrecha y empinada comunica todos los pisos.

Durante estos años el almacenamiento de granos y harinas no suele realizarse en los edificios de fabricación, sino que los agricultores o panaderos se encargan de ello. A esto se destinan los graneros de la vivienda y los antiguos silos, que se excavaban en tierra y se tapaban con paja y arena.

Estos tres tipos de molinos (malacates, de agua y de viento) coexisten en mayor o menor grado durante siglos hasta que se inicia la era industrial. Los inicios de las grandes fábricas de harinas en el mundo son muy difusos. Desde el principio de la industrialización todas las actividades mecanizadas se orientan hacia el incremento de la producción y, por otro lado, existe la posibilidad de usar nuevas fuentes de energía que se van incorporando a la vida cotidiana. Así, a mediados del siglo XIX ya prácticamente toda la industria textil europea había sustituido la rueda hidráulica por la máquina de vapor. Sin embargo, en la fabricación de harinas se opera un paso intermedio. Se trata de fábricas con diseño modernoy, sobre todo, con un nuevo tipo de molinos basado en rodillos estriados metálicos, que son accionados con baterías de ruedas hidráulicas. Se combinan así las técnicas más modernas de molienda con los sistemas de producción de energía tradicionales.

Los molinos estriados metálicos son los que van a marcar la diferencia esencial entre los sistemas tradicionales de molienda y las nuevas fábricas de harinas. Aparecen en Europa hacia 1860 y se instalan por primera vez en España en 1886. Además se van a inventar otras máquinas para la limpieza, cernido y selección de granos y harinas que, en muy pocos años, consiguen automatizar todo el proceso de fabricación de harinas que, hasta entonces, se realizaba fundamentalmente de forma manual (salvo la molienda). Estos avances se deben, principalmente, a varias empresas de fabricación de maquinaria, que en Europa compiten por promocionar la industrialización de la molienda de trigo y cuya aparición y desarrollo tiene interés histórico.

Durante el siglo XIX cambian los sistemas de producción agrícola y se produce la revolución industrial. Todos estos 
cambios afectan a las tipologías arquitectónicas. La aparición de industrias genera la necesidad de edificios en las que albergarlas. Aparecen nuevos materiales de construcción industrializados que se incorporan, muy especialmente, a la nueva arquitectura industrial. Este tipo de edificación tendrá características propias, aunque también influyen las tendencias arquitectónicas del siglo, neoclasicismo, eclecticismo, racionalismo, si bien de forma un tanto marginal.

Un material que entra con fuerza en la construcción industrial es el hierro en sus diversas modalidades. En la arquitectura textil inglesa se usa la fundición para pilares y hasta mediados de siglo incluso en vigas, pese a su mal comportamiento a flexión. La aparición, en 1856 del convertidor Bessemer, inicia el desarrollo de la producción masiva de acero que sustituirá, primero, a la fundición en las vigas de forjados, algo más tarde, al hierro forjado en los sistemas triangulados y, ya entrado el siglo XX, a la fundición para pilares. En España, la fabricación de acero comienza en 1885 .

Otro elemento constructivo que mejora su tecnología en este siglo es el ladrilloy, en general, los elementos cerámicos (Foto 1). En 1890 se empieza la mecanización de la fabricación y se emplean las galleteras para extrusionar. Desde mediados de siglo existían hornos industriales que mejoraron mucho la calidad de la cocción, aunque los "tejares" tradicionales coexisten con éstos hasta el primer tercio del siglo XX. Este elemento constructivo será primordial en la arquitectura industrial de cambio de siglo en España, recuperando formas mudéjares. En el caso concreto de las harineras, la importancia de este material es capital.

De menor importancia para los edificios que nos ocupan son la mejoras que se introducen en los conglomerantes hidráulicos, concretamente la aparición del cemento portland en 1824 (Aspdin), el desarrollo inmediato del hormigón y el empleo de acero, combinado con el hormi-

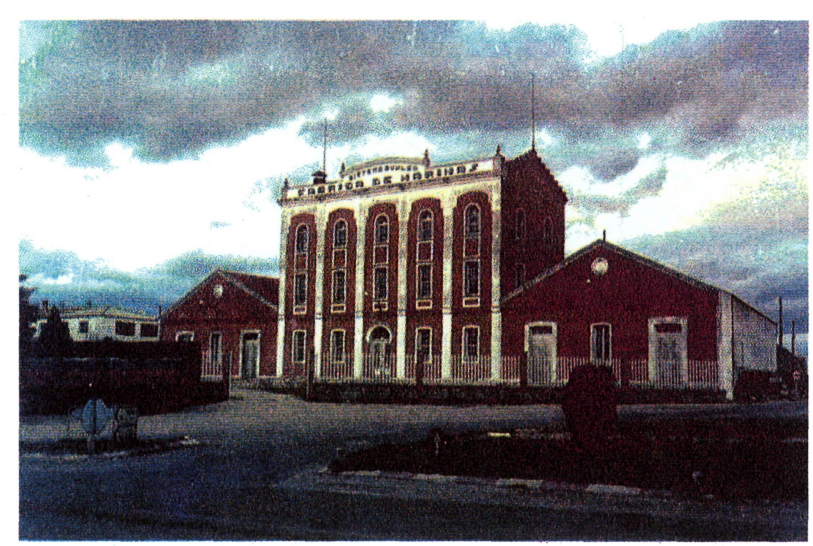

Foto l.- Fábrica de harinas con fachada de ladrillo visto. Olmedo (I'alladolid).

(c) Consejo Superior de Investigaciones Científicas Licencia Creative Commons 3.0 España (by-nc) gón, iniciado en 1867 (Monier) y perfeccionado con el empleo de redondos y estribos a partir de 1892 (Hennebique). En España las primeras fábricas de cemento son de los últimos años del siglo XIX, pero, con anterioridad, se importaba. En las fabricas de harinas el empleo del cemento en las estructuras no es generalizado, aunque hay algunos casos puntuales muy notables.

También se produjeron muchos avances en otros materiales, como el vidrio, que cambió en 1806 de sistema de fabricación, llegando a producir grandes paneles. Este elemento dio lugar en este siglo a la "arquitectura del vidrio y el acero" de gran influencia en la construcción industrial En el caso de las fábricas de harina, el vidrio no tuvo una importancia especial. También, desde mediados de siglo mejoran las técnicas tradicionales de producción de cerámicas decoradas (azulejos, baldosas, etc). En España se populariza el uso de pavimentos de gres policromo desde 1851 y más tarde se incorpora el mosaico hidráulico, obtenido por prensado de mortero de cemento y que será el pavimento más común en la construcción industrial española del cambio de siglo.

\section{Aparición y desarrollo de las fábricas de harina}

Las fábricas de harina son, junto con las bodegas, las alcoholeras y los mataderos, los primeros edificios de carácter industrial que se construyeron en el medio rural. Estas construcciones se comenzaron a realizar en España en la última década del siglo XIX y prosiguieron hasta la guerra civil española. Concretamente la construcción de harineras abarca todo este período, aunque el mayor número de ellas se fecha entre 1905 y 1925 . En estos años, la situación de los edificios industriales estaba enormemente condicionada por los medios de transporte. Tanto la recepción de materias primas como la expedición de productos tenían una influencia decisiva en la rentabilidad de las inversiones. Por esto no es de extrañar que la construcción de estas fábricas aparezca asociada, muy estrechamente, con el tendido de los primeros ferrocarriles, que permitian enviar la harina a los grandes centros consumidores, las ciudades. La alternativa al transporte por ferrocarril eran los carros de tracción animal, insuficientes para las fábricas de gran tamaño. También en las ciudades se construyeron harineras $y$, en este caso, el problema de transporte era el de las materias primas (el trigo). Para resolver el problema, el abastecimiento se hacía o bien de las zonas próximas a las ciudades $o$, nuevamente, por tren, mediante acuerdos con grandes productores

Otro factor muy importante en el establecimiento y proliferación de las fábricas de harina fue el suministro de energía. En España se han encontrado fábricas con mecanización hidráulica y con máquinas de vapor pero, en general, los dos sistemas energéticos más empleados fueron la energía eléctrica y los motores de combustión interna. El retraso en la aparición de las fábricas de harinas 
respecto a otras industrias españolas como, por ejemplo, las textiles que sí que llegaron a emplear comúnmente la máquina de vapor, produjo que su establecimiento en los pueblos y, desde luego, en las ciudades coincidiera en el tiempo con las primeras centrales de producción de energía eléctrica mediante pequeños saltos de agua. Es tan estrecha esta relación que, en algunos casos, en el mismo edificio, se realizaban las dos funciones, producción de energía eléctrica y fabricación de harinas (Foto 2). En cuanto a los motores de combustión interna se emplearon en aquellos pueblos donde no existía energía eléctrica y seguramente en algún caso sustituyeron a las máquinas de vapor, como sucedió en otras industrias de esta época. Las fábricas que utilizan este sistema suelen ser algo más tardias que las otras.

En los veinte años que duró el apogeo de las fábricas de harina se construyeron un gran número de ellas. No se ha podido determinar con exactitud este número pero con seguridad pasan de mil quinientas en toda España. Se puede decir que cada pueblo de las zonas productoras de trigo con una población media disponía de su propia fábrica. En el medio rural la construcción de fábricas de harina y las demás construcciones industriales supusieron un cambio muy grande en las técnicas y tipologías constructivas. El maestro de obras rural descubrió nuevas técnicas y materiales colaborando en la realización de estas edificaciones. El proyecto y la ejecución eran dirigidos, en la mayoría de los casos, por un arquitecto de la ciudad que no tenía reparos en transportar materiales nuevos desde una gran distancia y que adaptaba las tendencias arquitectónicas y constructivas del momento a sus disponibilidades presupuestarias. Éstas no eran tampoco muy escasas pues el concepto de los negocios que se tenía entonces era muy distinto al moderno. Los promotores veían la empresa como un legado familiar que debía pasar de padres a hijos y el edificio era el símbolo de ese negocio, por lo que su "solidez" y durabilidad debían estar garantizadas. El traslado de las nuevas técnicas y tendencias constructivas a la pequeña obra rural se produjo lentamente por dificultades

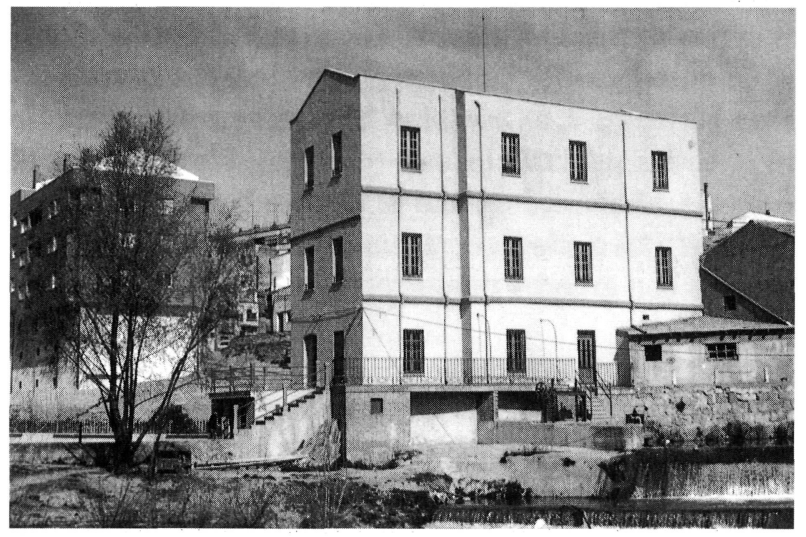

Foto 2.- Fábrica de harinas y minicentral eléctrica en Aranda de Duero (Burgos).

(c) Consejo Superior de Investigaciones Científicas Licencia Creative Commons 3.0 España (by-nc) económicas, pero la idea de innovación quedó fuertemente grabada en el constructor rural y supuso el inicio del fin de la arquitectura popular.

Las fábricas construidas en estas dos décadas tuvieron una historia muy diversa. Muchas de ellas (quizá un 30-35\%) funcionan en la actualidad y aún suponen un buen porcentaje de la harina que se fabrica en España. En estos casos la maquinaria ha sufrido una o dos renovaciones aunque todavía las hay que conservan la maquinaria original. El edificio en unos casos está intacto, en otros se ha reforzado en alguna forma sin alterar su aspecto y en otros se ha restaurado (en algunos casos la palabra restaurar es, realmente, un eufemismo). También se dan casos en los que se han hecho ampliaciones, sobre todo en el almacenamiento de granos y harinas, con la construcción de silos y almacenes anejos. Otras muchas fábricas (entre un 35-40\%) están abandonadas. Su estado es malo en general, en algún caso ruinoso. Sin embargo, existen otras que permanecen cerradas (y hasta vigiladas), donde todavía se conserva bien el edificio. En casi todas ellas los propietarios vendieron la maquinaria, por lo que sólo queda el edificio. En unas pocas están también las máquinas abandonadas, sobre todo en aquéllas en las que eran más antiguas y, por tanto, más difíciles de vender. Queda un porcentaje de fábricas, que se estima entre un 25 y un $35 \%$, que se reparte entre las que se han derribado y las que se han reconvertido para otros usos (5-10\%) (Foto 3$)$.

Después de la guerra civil española, el abastecimiento de pan a la población supuso una preocupación primordial durante diez a quince años. Sin embargo se construyeron muy pocas fábricas nuevas. Parece que la capacidad de producción se había sobredimensionado los años anteriores. Mejoraron, eso sí, los rendimientos y al final del período muchas fábricas habían cambiado la maquinaria. A partir de 1955, y sobre todo durante la década de los sesenta, se inicia un declive muy importante en el consumo de pan de la población española debido a la mejora del nivel de vida. Esto conduce a una orientación restrictiva de la

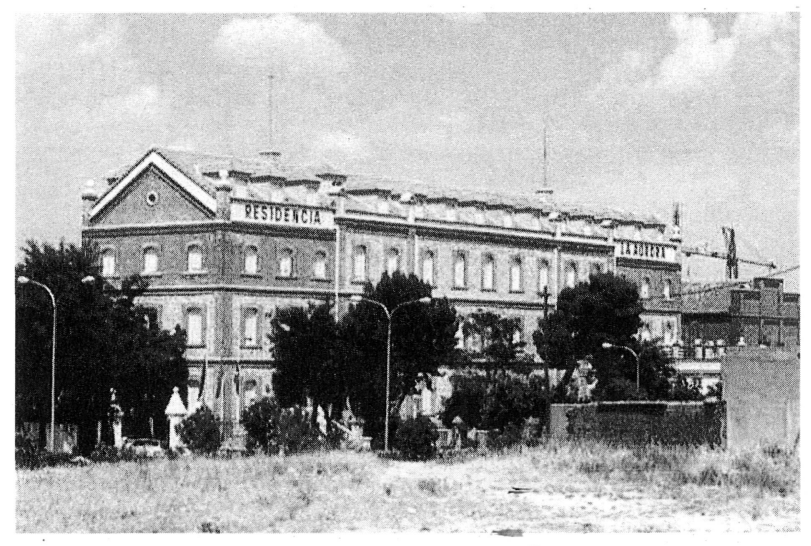

Foto 3.- Fábrica de harinas rehabilitada como residencia de ancianos Navalcarnero (Madrid) 
legislación en el sentido de no permitir la creación de nuevas harineras. En muy pocos años se cierran un porcentaje muy alto de ellas. Las que quedan mantienen escasamente la rentabilidad durante la década de los setenta reformando algunos edificios, añadiendo almacenes o silos y cambiando la maquinaria, pero apenas se establecen nuevas industrias. Por último, durante la década de los ochenta se produce el declive final de estas empresas. Se construyen nuevas fábricas, muy grandes y con tecnología muy avanzada que quitan mercado a las pequeñas empresas familiares y conducen al cierre de otro importante número de fábricas antiguas. Ésta es la situación actual, por lo que es previsible que en los próximos años se produzca el cierre de algunas harineras más. Más adelante se comentará la oportunidad y la utilidad de restaurar y reutilizar estos edificios.

\section{Proceso de fabricación de la harina a principios de siglo}

La distribución interior de la maquinaria y el proceso de fabricación son los que condicionan el diseñogeneral de los edificios (Foto 4). Tanto es así como que las empresas suministradoras de la maquinaria (Buhler, Daverio, Simon, etc.) proporcionaban a los promotores y arquitectos los planos de la fábrica casi completamente definidos, dejando libertad a los técnicos en temas estructurales y de detalles constructivos, pero poco en cuanto a organización y tamaño de los edificios. Conviene por lo tanto explicar, aunque sea someramente, cuál era el proceso de fabricación de harinas a principios del siglo XX.

\section{l) Recepción y almacenamiento}

En primer lugar se recibe el grano en carros o vagones de tren. Suele existir una báscula para el pesaje en la entrada de carros. Se realiza un reconocimiento visual de los granos $\mathrm{y}$, en algún caso, puede existir un pequeño laboratorio para investigar mezclas. El grano se almacena en naves laterales, bien a granel o, más frecuentemente, en sacos.

\section{2) Limpieza del grano}

Consiste en varias máquinas que realizan un cernido, clasificado, separación de metales, deschinado, lavado y secado del grano previamente a la molienda. Se sitúan dentro del edificio de fabricación, en una zona lateral, muchas veces en la misma zona en que se sitúan las celdas de harina, para ahorrar espacio. Suelen disponerse en dos pisos, aunque si fuera necesario pueden ir todas las máquinas en el mismo.

\section{3) Molienda}

Se realiza en molinos de rodillos metálicos, estriados y lisos, en número dependiente de la capacidad de producción. Todos ellos se disponen alineados en una planta, ya que son accionados por un eje y unas poleas. El eje se dispone por debajo de los molinos en una planta inferior. El girolo proporciona un único motor (térmico o eléctrico). Mediante poleas se transmite el movimiento a todas las máquinas de la fábrica que lo precisan. Una tarea muy

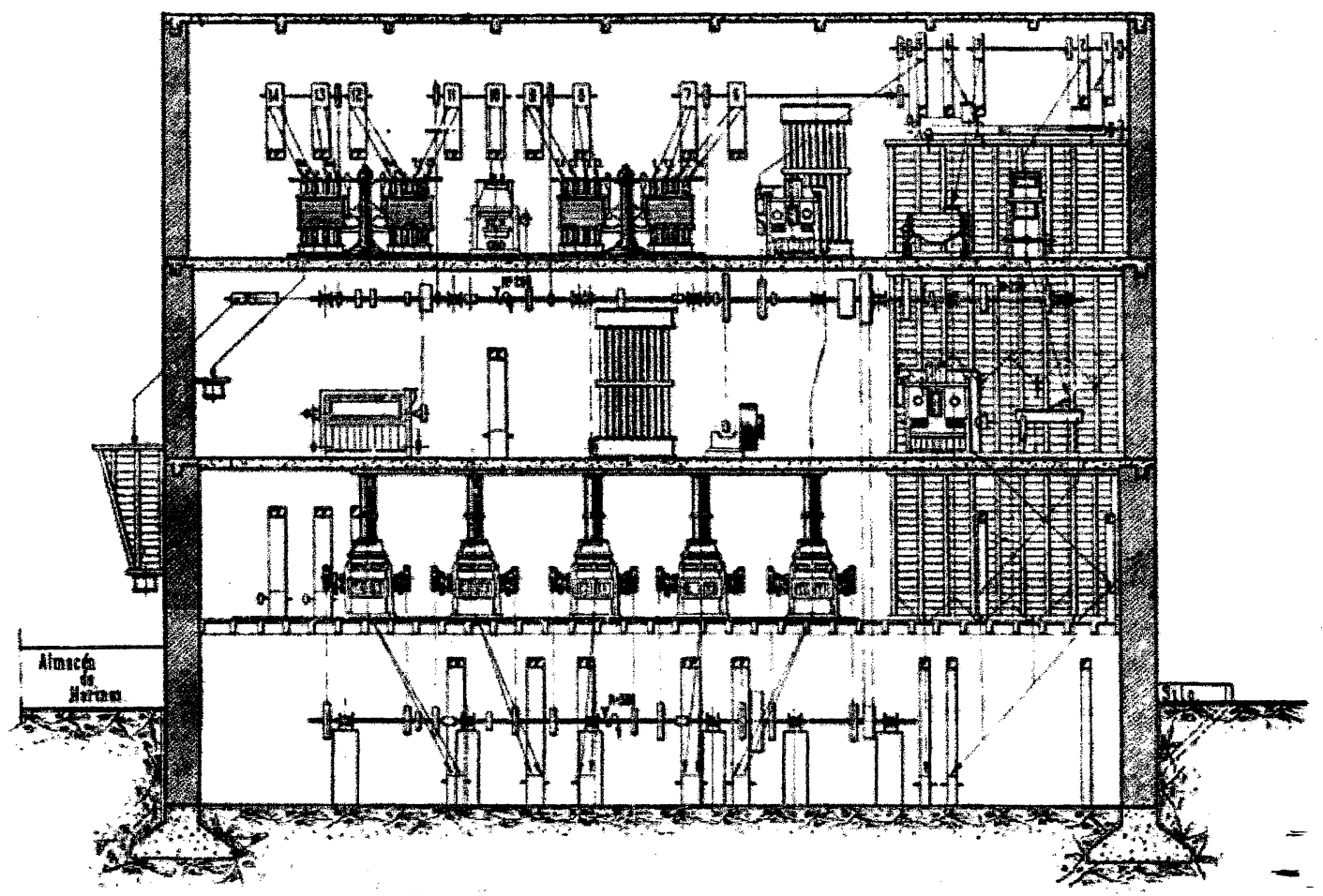

Foto 4.- Sección de una fábrica de harinas donde puede verse la disposición de la maquinaria. 
importante de la fábrica era el engrase de las poleas. Los molinos trabajan el grano o la harina para conseguir distintos grados de finura.

\section{4) Separación de la harina}

Una vez realizada la primera molienda se separa el salvado mediante cernedores especiales denominados, en aquel entonces, "plansichters". Se realizan sucesivas moliendas y cernidos y la harina, con alguna impureza de salvado, se limpia mediante sasores que utilizan corrientes de aire.

Las fases finales de la molienda se realizan con cilindros lisos. Existen innumerables posibilidades de combinación de molinos, cernedores y sasores para alcanzar el grado de finura y pureza de la harina deseados.

La disposición de estas máquinas obliga a proyectar edificios de, al menos, dos plantas, pues siempre se sitúan los cernedores sobre los molinos para facilitar la caída del grano por gravedad. Esta idea es análoga a la que ya se empleaba en los molinos de viento, aunque no es seguro que exista una inspiración directa en ellos.

\section{5) Almacenamiento y expedición}

La harina y los demás subproductos de la molienda se almacenan en celdas de madera hasta su ensacado y traslado a los almacenes desde donde se realiza su expedición.

\section{6) Movimiento del grano}

El trigo asciende hasta las distintas plantas mediante elevadores de cangilones y desciende por gravedad, usando tuberías de madera de sección rectangular. En ocasiones se realiza un ensacado en las plantas superiores, de harina, salvado o desechos de la limpieza. En este caso, se disponían originales rampas de madera que atravesaban los forjados hasta la planta baja o ascensores muy rudimentarios, movidos por las inevitables poleas.

\section{Diseño del edificio}

El proceso productivo descrito condujo a los técnicos fabricantes de la maquinaria a unos diseños característicos, luego imitados profusamente por los proyectistas. El diseño más corriente consistía en un edificio de planta rectangular donde se realizaban la limpieza del grano, la molienda y la separación y purificación de la harina. Este edificio disponía de tres plantas. En la planta baja se situaban principalmente los molinos, sobre un forjado a media altura (entre 0,5 y 1,5 m), bajo el cual discurría el eje de accionamiento de las máquinas y era atravesado por las poleas que movían los molinos. Frente a ellos queda un espacio para circulaciones. Al final del eje, también en la planta baja, pero en una sala aparte, estaba el motor
En la segunda planta se situaba una batería de sasores que descargaba sobre los molinos o al elevador para las celdas de harinas. En la tercera planta estaban los plansichters. En un lateral de las tres plantas se situaban celdas de madera para el almacén de harinas y salvados previo a su ensaque y las máquinas de prelimpia del grano que ocupan menos espacio que las anteriores.

La gran cantidad de polvo que se produce, con el riesgo de incendio y las molestias para los trabajadores que ello conlleva, obliga a proyectar grandes y numerosas ventanas, que caracterizan y embellecen las fachadas.

Solían tener entre ocho y diez metros de anchura, por lo que los dos forjados se dividían con una fila de pilares intermedios y sus correspondientes vigas carreras, sobre las que apoyaban las viguetas. En el otro extremo, las viguetas apoyaban sobre las fachadas, que actuaban de muro de carga. En ocasiones, las vigas son las que van de fachada a fachada y las viguetas siguen el eje principal del edificio. La planta superior podrá resolverse de dos maneras, o bien quedará diáfana mediante una cercha que forma una única nave a dos aguas, o bien se dividirá también en dos, dando lugar a dos naves adosadas. La primera solución es más común, pero cuando las cerchas son de madera se recurre, en ocasiones, a la segunda.

En muchos de los edificios sobresale una torre por encima del tejado en la que se disponía la cabeza de los elevadores de cangilones para la distribución a los plansichters. Esta torre produce un efecto estético agradable, bien aprovechado en la mayoría de los casos (Foto 5).

No obstante lo anterior existe una cierta variedad en los diseños. Por ejemplo, las fábricas más pequeñas sólo tienen dos plantas, situando los cernedores y sasores en la planta superior. Tampoco suelen tener torre de elevadores, aprovechando la mayor altura de la cubierta y el menor alejamiento de las máquinas. Por el contrario las harineras más grandes pueden tener cuatro o cinco plantas, pues dividen la entreplanta sobre la que van los molinos, aprovechando

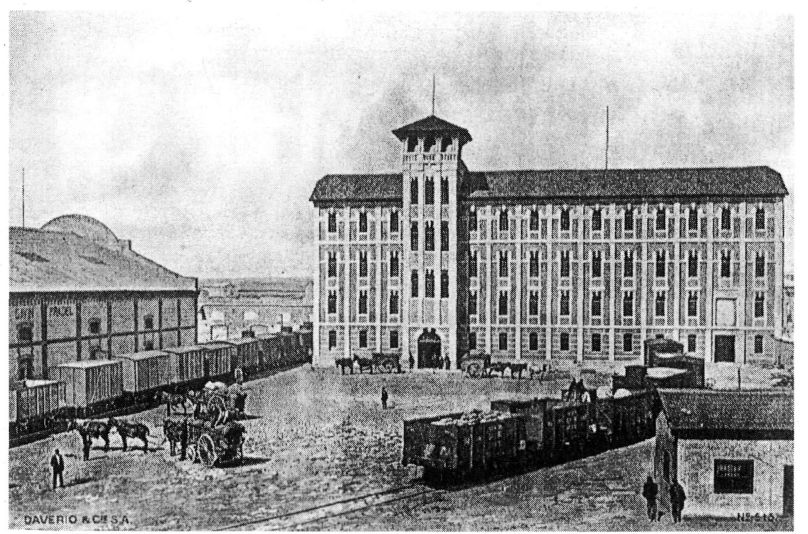

Foto 5.- Lámina representativa de una fábrica de harinas. Tardienta (Huesca).

http://informesdelaconstruccion.revistas.csic.es 
la planta baja para prelimpia y recepción, pudiendo, además, disponer de alguna planta más de cernido o prelimpia.

Para el almacenamiento de los sacos de trigo, de harina y de salvado se disponen salas de almacén en el edificio principal o bien naves laterales, de menor altura que la principal, con dos posibles disposiciones, de eje paralelo al del edificio principal o de eje perpendicular al del edificio principal. En otras ocasiones, estas naves de almacén se independizan totalmente del edificio de fabricación, aunque esto dificulta sobremanera el movimiento de las materias. En todos los casos, estas naves cuentan con gruesos muros para poder soportar los posibles empujes.

El conjunto de edificios descrito se sitúa en un patio de tamaño variable, aunque con un porcentaje de superficie edificada mucho mayor que en las industrias actuales. Esto crea la sensación de poco espacio para circulaciones, pero no se debe olvidar que en este patio se recibían carros con tracción animal.

La situación de las fábricas dentro de las poblaciones es variable. En muchos casos, como ya se ha indicado, la situación está condicionada por las vías del tren y entonces las fábricas quedan algo alejadas de las poblaciones. Cuando no se daba esta circunstancia, las fábricas se situaban en las afueras de las poblaciones. El resultado es que al crecer éstas, las fábricas han quedado en el interior de los núcleos urbanos. Esto es molesto si la fábrica sigue funcionando y, si está cerrada, se convierte en un edificio apetecible por el valor del solar. En las poblaciones de mayor desarrollo, sobre todo en las capitales de provincia, esto ha sido fatal para muchos edificios.

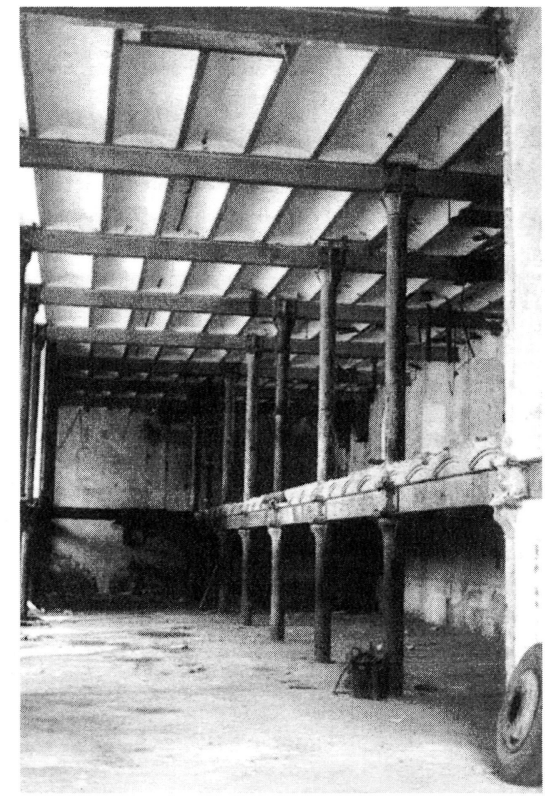

Foto 6.- Estructura caracteristica de una fábrica (c) Conlsejo Supleriorudernvéstigaciones Científicas Licencia Creative Commons 3.0 España (by-nc)

\section{Materiales y unidades de obra}

Como ya se ha indicado las fábricas de harina suponen la llegada al mundo rural de la nueva edificación industrial, que recoge y mezcla estilos y materiales aparecidos durante el siglo XIX. La arquitectura del hierro y el vidrio, la arquitectura ecléctica y la modernista tienen reflejo en estos edificios, pero también toman elementos de la arquitectura popular, la arquitectura vernácula y, en algún caso, la arquitectura árabe y la mudéjar. Veamos los elementos constructivos más comunes encontrados.

\section{l) Cimentaciones}

Poco se ha podido averiguar sobre las cimentaciones, pues existe muy poca información de proyectoy, en los edificios, es difícil conocer las características de la cimentación. No obstante, podemos deducir que son de mampostería, tomada unas veces con mortero de cal y otras con mortero de cemento o mezcla de ambos, por ser, éste, un aglomerante que ya era conocido en la edificación industrial urbana.

\section{2) Estructuras}

Las cargas las soportan verticalmente las fachadas por un lado y una o dos filas de pilares interiores por el otro. Estos pilares las más de las veces son de fundición, con la ventaja que tenía de su gran resistencia a compresión. Además podían utilizarse, si era preciso, como bajantes de las aguas pluviales (Foto 6). Para unirse con las vigas del forjado usaban unas piezas especiales, también de fundición. Sirvieron, además, como elemento ornamental, imitando los capiteles de los estilos clásicos, dórico, jónico y corintio, quizá más el primero. Este elemento está tomado de la arquitectura del vidrio y el hierro y del estilo neoclásico del siglo XIX. Fue el único de los materiales nuevos que llegaron a la zona rural de mano de estas industrias, que no se incorporó a la arquitectura popular. En ocasiones, también se usaron, como pilares, los perfiles de acero en $U$, bien empresillados o con forro continuo de chapa. Las uniones de acero se ejecutaban por roblonado y en algún caso atornillado. Alguna otra fábrica de menor entidad llegó a utilizar pilares de madera escuadrados.

Los forjados de los pisos suelen ser de dos tipos, o bien de vigueta de perfiles laminados en I con bovedilla de doble rosca de ladrillo o bien de viguetas de madera escuadrada y entablado. En ambos casos, las viguetas descansan sobre vigas de acero laminado en I, que van de pilar a pilar, siguiendo el eje longitudinal del edificio.

La estructura de cubierta siempre es una cercha. En las fábricas de mayor anchura (a partir de seis o siete metros) está formada por perfiles de acero laminado casi siempre dobles, unidos entre sí mediante presillas. Los_nudos se resuelven por roblonado a cartelas. Los perfiles suelen ser angulares. Se usan tanto los de lados iguales como los de lados desiguales. Las cartelas, en muchos casos, se recortan http://informesdelaconstruccion.revistas.csic.es 
con formas redondeadas. Cuando la anchura del edificio es menor de seis metros, o en la planta superior se divide la cubierta en dos naves, suele emplearse la cercha de escuadrías de madera. En este caso el tipo de cercha es el español, de un solo cuadro o de cuadros múltiples, sustituyendo entonces los tirantes de madera por redondos de acero. En las metálicas se usan tanto el tipo español como el inglés o el Polonceau, siempre de cuadros múltiples. En alguna ocasión, en la cercha de madera, se sustituye el tirante inferior por un redondo de acero. No aparecen, sin embargo, piezas de fundición en las cerchas metálicas, que se usaban como tornapuntas en las cerchas de edificios industriales urbanos con mucha frecuencia.

\section{3) Soleras}

Debemos diferenciar en las soleras el caso de la planta baja y el de las demás, pues éstas quedan condicionadas por el tipo de forjado. En cualquier caso, parece que el tipo de solera más común era el de baldosas de mosaico hidráulico, aunque formando dibujos no tan sofisticados como los de algunas viviendas de aquella época. Las baldosas son de tamaños diversos pero suelen ser de $20 \times 20 \mathrm{~cm}$ o menores. Compite con el mosaico hidráulico el pavimento de mortero de cemento, que, en muchos casos, no se sabe si es original o una reparación posterior. Son menos comunes los pavimentos de arcilla cocida, que era el otro sistema utilizado habitualmente. En este caso solía emplearse el denominado baldosín catalán o bien baldosas del mismo material que los ladrillos tochos. En las plantas superiores se usan estos mismos sistemas (mosaico y mortero) salvo cuando el forjado es de viguetas y tableros de madera, en cuyo caso los tableros sirven, al mismo tiempo, de pavimento.

\section{4) Fachadas}

En casi todos los casos, las distintas fachadas del edificio de fabricación son diferentes. Suele haber una fachada principal más ornamentada por la que se accede a la fábrica. Normalmente existe una sola puerta de entrada. Un elemento muy destacado de las fachadas de las harineras son las ventanas. Al contrario que la mayoría de los edificios industriales urbanos de la época, éstas son grandes y numerosas, embelleciendo el exterior y proporcionando una gran luminosidad interior. La razón de su existencia no es estética, sino funcional, dado que la industria produce una gran cantidad de polvo que, además de molestar y dificultar el trabajo, es peligroso, por su facilidad de provocar explosiones. En las industrias actuales la eliminación de este polvo se realiza muy eficientemente con máquinas extractoras, pero entonces el mejor sistema era establecer corrientes de aire por medio de numerosas y espaciosas ventanas.

Los materiales con los que se realiza la fachada deben ser resistentes debido a su importante misión como muro de frecuentes las fachadas de mampostería careada combinadas, las más de las veces, con refuerzos y adornos de ladrillo (Foto 7). Normalmente estos refuerzos siguen la división de los pisos en horizontal y las líneas de pilares en vertical, sirviendo de apoyo a las cerchas de la cubierta. También es frecuente que rematen las esquinas y sirvan para formar los aleros de la cubierta. Además se usa el ladrillo en muchas fachadas para enmarcar los huecos, formando jambas, dinteles y alféizares o en las cubiertas para impostas y antepechos, tanto de los hastiales laterales como de la fachada principal. En todos los casos se aprovecha el ladrillo como elemento ornamental, haciendo dibujos y grecas o formando celosías. Otro material que sirve de refuerzo y adorno de las fachadas es la piedra de sillería, que se combina, en ocasiones, con el ladrillo y la mampostería. Sobre todo se puede encontrar en las esquinas del edificio.

La segunda forma más corriente de realizar las fachadas es mediante el ladrillo visto. Este sistema era el más común en la edificación industrial urbana, pero en el medio rural los arquitectos parecen influenciados por la construcción popular y recurren más habitualmente a la mampostería. Las fachadas de ladrillo visto son muy bellas, pues el ladrillo se aprovecha para decorar y realizar formas geométricas imitando el estilo mudéjar. En este caso son muy comunes los refuerzos y adornos de sillería.

Finalmente, también en otras harineras, las fachadas son de mampostería o ladrillo en las que después se ha realizado un enfoscado con mortero de cemento. A veces quedan vistos los refuerzos y adornos de ladrillo. El mortero puede quedar liso o dibujarse sobre él imitaciones de sillería. En ocasiones los enfoscados de las fachadas son de una reforma posterior a la construcción del edificio y ocultan la fachada original de mampostería o ladrillo visto.

\section{5) Tabiques y divisiones interiores}

Las fábricas de harinas son diáfanas por lo que son muy escasos los tabiques y divisiones interiores. Los que se han estudiado son siempre de ladrillo enfoscado.

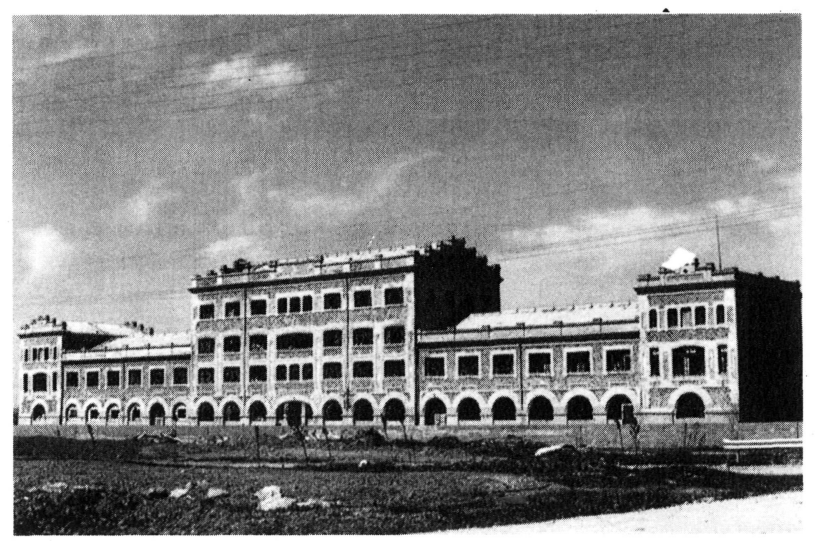

Foto 7.- Harinera con fachada de mampostería y ladrillo vistos. Pantoja (Toledo). 


\section{6) ('ubierta}

La cubierta del edificio principal puede ser a dos o cuatro aguas, siendo más corriente la primera. Cuando el edificio se remata con dos naves adosadas, la cubierta es doble, con recogida central de aguas. Dos materiales compiten en la formación de las cubiertas: la teja curva, más tradicional y muy conocida en el medio rural y la teja plana de encaje que es nueva y fue introducida en la construcción rural a través de los primeros edificios industriales agrarios. A raíz de su aparición en las primeras industrias agrarias su empleo se extendió mucho y durante algunos años hizo seria competencia a la teja curva en la edificación rural. Hasta la década de los sesenta este material de cubierta tiene una enorme importancia en todos los edificios rurales, tanto industriales como alojamientos de ganado y viviendas.

Las tejas se sustentan de tres posibles formas. La primera consiste en realizar un entramado de madera con correas, cabios y listones al que se fijan las tejas planas mediante atado con alambre. También se pueden usar tejas curvas que entonces van sobrepuestas. Generalmente este sistema exige un falso techo interior bien en los tirantes de las cerchas o bien en los faldones de la cubierta. La segunda forma es organizar un entramado menos denso y dejar una superficie plana mediante tableros de madera de tamaños variados. Sobre esta superficie se fijan las tejas con mortero. La tercera forma es análoga a ésta, pero el tablero que se construye es de ladrillo o rasilla. De los tres sistemas el más corriente es el segundo.

\section{7) Huecos}

Ya se ha indicado antes que son grandes y numerosas las ventanas. En la mayoría de los casos son rectangulares, con mayor altura que anchura. El ancho suele estar entre 1 y 1,5 metros y la altura entre 1,5 y 2 metros. Son de dos hojas, predominando la carpintería de madera. En muchos casos los vidrios son pequeños, con dimensiones de 20 ó 30 centímetros, por lo que la ventana aparece muy subdividida. No obstante estas pautas generales la variedad es muy grande. En la última época, pasado 1930, parece aumentar la tendencia a que el ancho supere a la altura y a usar la carpintería metálica.

Las puertas no son muy grandes. Suelen ser de madera, con dos hojas, muchas veces haciendo dibujos con los tablones, aunque su aspecto general es muy sobrio.

Tanto en las puertas como en las ventanas son muy comunes los dinteles con una ligera curvatura. En ocasiones y sobre todo en las puertas, se usan arcos de ladrillo de medio punto, ojivales y de herradura.

\section{8) Escalera}

La escalera principal da acceso a las distintas plantas del edificio. En casi todos los casos es una escalera estrecha de

(c) Consejo Superior de Investigaciones Científicas

Licencia Creative Commons 3.0 España (by-nc) pendiente pronunciada. Existen bastantes diferencias entre unas y otras. Las hay enteramente de madera, zancas, peldaños y barandilla. Las hay que combinan las zancas y los peldaños de madera con la barandilla de hierro forjado. También las hay con peldaños de baldosa de gres o mosaico hidráulico con los cantos de madera. Finalmente, la estructura de sustentación puede emplear, además de la madera, los perfiles de acero y el tabique de ladrillo.

Además pueden existir otras escaleras como la de acceso a la puerta de entrada, que existe siempre que la entrada se sitúe al nivel de los molinos, pues como ya se ha explicado, el eje de accionamiento quedaba en una entreplanta inferior. En algunas harineras esta escalera de acceso al edificio es un elemento de adorno de gran importancia mientras que, en otras, son unos simples peldaños sin ninguna gracia. En los edificios cuya entrada se hace al nivel del suelo y que, por lo tanto, dan acceso a la entreplanta de accionamiento, lo que sucede es que hay una escalera interior de ascenso a la meseta donde se sitúan los molinos. Suele ser toda de madera.

\section{9) Adornos}

Nos referimos principalmente al adorno del exterior del edificio, aunque en el interior también en algunos elementos constructivos puede apreciarse la intención estética además de la meramente funcional, como en los pilares de fundición, en los forjados de madera, en algunas soleras de mosaico hidráulico o en la escalera.

En las fachadas se usan principalmente dos elementos de adorno, los ladrillos y los azulejos. Los ladrillos sirven para realizar dibujos superficiales en las fachadas de ladrillo visto y para formar elementos divisorios tanto en fachadas de mampostería como en las de ladrillo y en algunas fachadas enfoscadas. Estos elementos divisorios pueden ser verticales $u$ horizontales. Los verticales coinciden normalmente con líneas de pilares y pueden ser, a su vez, verdaderos elementos estructurales de refuerzo o no. Los horizontales se sitúan generalmente dividiendo las distintas plantas del edificio formando, además, grecas y resaltos. Puede haber más elementos de adorno horizontales de ladrillo, que en el caso de mampostería llega a dar lugar al aparejo denominado toledano. Otra forma de adorno con el ladrillo son los marcos que rodean los huecos, puertas y ventanas, que en ocasiones son, a la vez, elementos estructurales. Estos marcos son de grosor variable y pueden formar dibujos y dar relieve.

También se emplea el ladrillo como elemento de adorno en la formación de cornisas y en las impostas que ocultan la cubierta. En las cornisas se emplean los sistemas de adorno habituales mediante la combinación de hiladas de ladrillo con distintos aparejos y disposiciones y también con el uso de formas de ladrillo redondeadas. En las impostas se distinguen las de la fachada principal que pueden ser un simple murete de ladrillo en el que se disponen rótulos y/ 
o azulejos con su correspondiente vierteaguas o bien se forman impostas decoradas en ladrillo formando celosías y dibujos. Las impostas de las fachadas laterales o hastiales pueden ser rectangulares, siguiendo la altura de la imposta de la fachada principal, pero es más corriente que se adapten a la inclinación de la cubierta formando escalones o con formas redondeadas.

Junto con el ladrillo, el elemento de decoración más profusamente utilizado en las fachadas son los azulejos. Dan una nota de color muy interesante en las fachadas. Se empleaban para escribir los rótulos de la fábrica, normalmente el nombre, el sistema de fabricación $y$, a veces, también el arquitecto y el año de la inauguración. Además podían formarse dibujos y anagramas de la empresa. Desgraciadamente en muchas de las fábricas estos elementos han desaparecido.

También se usan elementos de piedra con fines decorativos, bien sea sillares de refuerzo en esquinas o zócalos o pináculos de cubierta y balaustradas en la escalera de entrada o en las impostas de la cubierta.

En las fachadas enfoscadas la decoración que no se realiza con ladrillo visto se confia a elementos que dan relieve a la fachada, cornisas, salientes en las esquinas, etc. y también se recurre a pintar con distintos colores y a rayar o abujardar el mortero, imitando la piedra.

\section{Estado de los edificios y rehabilitación}

Comoya se ha indicadola situación actual de estos edificios es muy diversa. Nada se puede hacer ya respecto a los edificios demolidos. En aquéllos que siguen funcionando como fábricas de harinas sería conveniente vigilar que las adecuaciones, ampliaciones oadaptaciones que se hicieran no fueran en detrimento de la construcción original, especialmente aquellos elementos más destacados desde el punto de vista estético o histórico. Esta misión corresponde claramente a los arquitectos municipales, para los que sería bueno disponer de alguna de la información recogida en este trabajo. Por último, están los edificios abandonados en distintos grados de deterioro que fácilmente podrían reha- bilitarse y aprovecharse. Asi se ha hecho en algunos casos como en Aranda de Duero, en Burgos, donde la antigua fábrica ha sido rehabilitada por los alumnos del Taller Municipal y finalmente se ha convertido en su sede. En Navalcarnero, en Madrid, los propietarios de la harinera han conservado el edificio, reformándolo y convirtiéndolo en residencia de ancianos. Parece que un buen destino de estos edificios sería el de locales públicos de tipo social o cultural teniendo en cuenta su luminosidad y diafanidad y, en este sentido, deberían hacerse estudios particulares para cada uno de ellos.

Lo peor es que caigan en el olvido y no se estudien sus posibilidades antes de llegar a la demolición.

\section{REFERENCIAS}

(1) AYUGA, F. (1989): "Evolution of agricultural buildings in Spain. Its influence in rural landscape". $11^{\circ}$ Internacional Congress on Agricultural Engineering. Dublín. Ed. Baikema vol. 2 pp. $1199-1205$.

(2) AYUGA, F; GARCÍA, A. L. (1992): "Fábricas de harina de principios del siglo XX". Trabajo de investigación no publicado. Financiado por la Dirección General para la Vivienda y la Arquitectura.

(3) DAL SASSO,P.;PICUNO,P. (1996): "Il recuperofunzionale del fabricati agro-industriall di valore storico nel contesto territoriale. Revista di lngegneria Agraria. Anno XXVII, ${ }^{\circ}$ 2 , pp. $111-122$.

(4) FAILLA, A.; DI FAZIO, S. (1994): "The reuse of tradicional farm buildings in the context of a changing agriculture". $12^{\circ}$ International Congress on Agricultural Engineering. Milán. Vol. l pp. 661-670.

(5) GARCÍA, J. L. et al. (1985): "Recuperación de los molinos del Tajuña y su entorno". Comunidad de Madrid.

(6) IAN JACK, R. (1992): “Australia”. Industrial Heritage'92. National Reports. 8th International Conference on the conservation of the Industrial heritage. Madrid. CEHOPU, pp 9-14.
NOTA: El presente artículo se ha basado, fundamentalmente, en el trabajo de investigación "Fábricas de harina de principios del siglo XX", realizado por sus autores y financiado por la Dirección General para la Vivienda y la Arquitectura. 